\title{
Proposed Rule from HCFA on Notification of Patients and HIV Testing After Receipt of Potentially HIV-Infectious Blood or Blood Products
}

The Health Care Financing Administration (HCFA) published for comment a Proposed Rule in the Federal Register of June 30, 1993 (p. 34977ff), amending the conditions of participation in the Medicare Program for Hospitals. The proposed rule would require hospitals to notify a blood transfusion recipient's attending physician when potentially HIVinfectious blood or blood products have been administered. If the physician is unavailable or declines to notify the recipient of the need for HIV testing and counseling, the hospital must do so. Hospitals receiving service from outside blood banks would be required to have an agreement that specifies that the blood bank notify the hospital if potentially HIV infectious blood or blood products have been made available to the hospital.

HCFA will consider written comments on this proposed rule, if they are received by 5:00 PM on August 30, 1993, at HCFA, DHHS, Attention BPD-633-P PO. Box 26688, Baltimore, MD 21207.

Further information on the comment process is available from Joyce Eng at (410) 9664619.

HCFA indicates that it is particularly interested in receiving comment on the appropriateness of the implementation of this requirement as part of the Medicare standard, or whether it should be a part of the Food and Drug Administration's requirements applicable to blood banks. The proposed rule details the definition of "HIV infectious," the procedures (including time frame) for notification of attending physician or patient, and the record keeping requirements. The American Hospital Association is coordinating a response to HCFA on this proposed rule; for information, contact Karen Kroc at (312) 280-6511. SHEA members may wish to make additional comments directly.

\section{SHEA Training Course in Hospital Epidemiology}

The Society for Hospital Epidemiology of America (SHEA), the Centers for Disease Control and Prevention (CDC), and the American Hospital Association (AHA) again will co-sponsor their popular hospital epidemiology training program this fall.

The course is scheduled for September 12-14, 1993, in Seattle, Washington and is being organized and taught by representatives from some of the most influential healthcare and prevention organizations in the country.

The course is intended for infectious disease fellows, new hospital epidemiologists, and infection control practitioners who desire additional epidemiological training. It will emphasize hands-on exercises in which participants work in small groups to detect, investigate, and control epidemiologic problems encountered in the hospital setting. These working sessions are supplemented with lectures and seminars covering fundamental aspects of hospital epidemiology.

There are a limited number of scholarships available for infectious disease fellows who need outside financial support to attend the course. Scholarships are made possible in part by an educational grant from Merck Human Health Division.

Further course and scholarship information is available from: Ian Dockrill, SHEA Meetings Department, 875 Kings Highway, Suite 200, Woodbury, NJ 080961720. Telephone (609) 845-1720. FAX (609) 853- 0411.

Brief items of interest for the SHEA News or Newsletter may be sent to C. Glen Mayhall, MD, SHEA Newsletter Editor, Division of Infectious Diseases, Department of Medicine, University of Tennessee, Memphis, 956 Court Ave., Memphis, TN 38163; FAX (901) 528-5854. Copy should be typed, double-spaced, and should not exceed five pages. 